\title{
FGFR3 NP_000133.1:p.S371C
}

National Cancer Institute

\section{Source}

National Cancer Institute. FGFR3 NP 000133.1:p.S371C. NCI Thesaurus. Code C128909.

A change in the amino acid residue at position 371 in the fibroblast growth factor receptor 3 protein where serine has been replaced by cysteine. 